\title{
Sis peces teatrals reaparegudes del teatre valencià
}

\section{Six disappeared theater plays from the valencian theater}

\author{
JoAna Sales Baviera \\ joasaba@doctor.upv.es
}

ORCID: 0000-0003-3706-985

Universitat Politècnica de València

\begin{abstract}
Resum: Durant el període del s. xix, el teatre valencià representat pel gènere de sainet, anomenat per molts estudiosos obreta de fer riure, va tindre una repercussió molt marcada. Però no el teatre culte, que per circumstàncies, entre les quals es trobava la mancança d'una normativa lingüística, ortogràfica i gramatical, no va arribar a ser una de les prioritats dels escriptors noucentistes valencians. Llavors, trobem com el sainet escrit amb el seu registre col loquial, és el gènere literari que representa l'anomenat teatre valencià de l'època. Gràcies a llegats i col leccions, els investigadors han anat classificant i recopilant aquestes obres que formen part de la nostra literatura. En aquest estudi donarem a conèixer sis peces teatrals corresponents al segle esmentat. Aquestes peces, les quals han romàs desaparegudes, les hem pogut extraure gràcies al llegat d’un dels teatres més importants que ha tingut la ciutat de València, el Teatre Russafa.
\end{abstract}

Paraules clau: teatre valencià, sainet, Teatre Russafa, València

\begin{abstract}
During the period of the 19th century, the Valencian theater represented by the genre of one act play, called by many scholars a work of laughter, had a very marked repercussion. But not the cult theater, which due to circumstances, among which was the lack of linguistic, orthographic and grammatical regulations, did not become one of the priorities of the Valencian xix century writers. Then, we find how the one act play written with its colloquial register, is the literary genre that represents the so-called Valencian theater of the time. Thanks to legacies and collections, researchers have been classifying and compiling these works that are part of our literature. In this study we will present six plays corresponding to the aforementioned century. We have been able to extract these pieces, which have disappeared, thanks to the legacy of one of the most important theaters in the city of Valencia, the Theater Russafa.
\end{abstract}

Keywords: valencian theater, one act play, Russafa Theater, Valencia

DATA PRESENTACIÓ: 01/03/2021 ACCEPTACIÓ: 09/04/2021 ·PUBLICACIÓ: 01/06/2021 


\section{Introducció}

El treball que presentem, tracta de la redescoberta de sis peces teatrals valencianes noucentistes. Unes peces que han estat durant més de cent anys amagades sense veure la llum. L'Almanaque de Las Provincias, en les seues publicacions anuals, on feia un recompte de la vida del cap-i-casal entre elles dels teatres de la ciutat, ens va mostrar l'existència d'aquestes obres, però no així de la seua autoria.

Després d'haver-les trobat al llegat de la família de Rafael Culla, qui van ser empresaris durant mitja centúria d'uns dels teatres més importants de València, el Teatre Russafa, la nostra recerca ens ha dut a la quasi certesa que almenys cinc d'aquestes peces no han estat mai impreses i que les versions originals manuscrites són les úniques que existeixen.

Hem fet un exhaustiu repàs a arxius i fons existents sobre el teatre valencià i gràcies a treballs com els de Severí Guastavino Robba i Guillem Guastavino Gallent, Un siglo de teatro valenciano. Materiales para su estudio, on hem pogut trobar el nom de cinc de les peces de les quals parlem, però sense cap descripció i sense nom d'autor, cosa que ens fa pensar que Guastavino va saber de la seua existència segurament per la publicació de l'Almanaque de las Provincias (Guastavino 1974).

En el Fons de Teatre Valencià de la Biblioteca Bas Carbonell, amb una recopilació de 1.537 obres (Reus i Bas 1994), així com en el Fons de Teatre Valencià a les Biblioteques de Barcelona, amb una recopilació de 1.626, totes elles molt ben classificades i detallades no hi ha menció d'aquestes sis peces (Vázquez 1987).

La Universitat d'Alacant en la Biblioteca de Filosofia i Lletres ofereix una secció de Fons Teatral Valencià, on hi ha un recull d'obres de teatre popular valencià dels segles XIx i xx. Aquesta tasca dirigida pel professor Gabriel Sansano juntament amb investigadors molt coneixedors del tema, com Jaume Lloret i Francesc A. Reus, té la finalitat de convertir-se en un punt de referència en l'estudi del teatre popular valencià. En la seua base de dades Teatre popular valencià-versió wiki-, hem pogut trobar també el nom de cinc de les peces del nostre estudi, però catalogades amb una data aproximada d'estrena i sense nom d'autor.

Les obres en qüestió són totes elles d'autors valencians molt coneguts en els escenaris teatrals de la València d'acaballes del s. XIx: Consumos y consumeros d'Eduardo Escalante Feo; Un incrèdul d'Estanislao Mañez Vidal; Lo qu'importa es relluir i Un barber de contrabando de José Campos Marté; Cachet y Colom i Valencia de Juan Colom i Sales.

Amb el present estudi, la nostra intenció és la d'aportar més informació de la que existeix fins ara donant-les a conèixer junt el nom dels seus autors, la temporada teatral, els artistes de la companyia que les van estrenar i la seua data d'estrena. A més, però, volem fer una incursió al gènere, sainet, en el sentit que sols una d'aquestes obres ha estat descrita com a tal pel seu autor. 


\section{El sainet i les seues accepcions}

En la segona meitat del s. xix, però sobretot en el període que abasta la Restauració, observem la copiosa producció de sainets i de teatre costumista que hi va sorgir al País Valencià. Moltes d'aquestes obres van ser impreses al poc de ser estrenades, algunes han quedat manuscrites en els llegats, com és el cas que ens ocupa, altres han desaparegut, però també hi va haver reedicions de moltes d'elles que es van incloure en diverses biblioteques. Sanchis Guarner ens recorda un llistat d'aquestes edicions: La Moma (1885) dirigida per Rafael Ma Liern i V. Ripollés; El Cuento del Dumenge (1908-1909) dirigit per Luís Bernat i Ferrer, i en (1914-1921) per Vicent Carceller; La Comèdia Llevantina (1919), 37 nùmeros; Nostre Teatre (1921-1922) dirigida per Vicent Carceller, 67 números i en una segona època (1930-1931) per Jesús Morante Borràs; Teatro Valencià (1925-1928), dirigit per Rafael Gayano, 127 números; Galeria d'obres valencianes (1927-1928) dirigida per Josep Ma Molas, 60 números; Nostres comèdies (1930), dirigida per M.Soto i Lluch. (Sanchis Guarner 1980: 9)

En el Fons Teatral Valencià de la Biblioteca de la universitat d'Alacant, podem consultar un llistat de catorze d'aquestes edicions.

En el s. XVII i inicis del XVIII, la paraula sainet era utilitzada com a nom genèric aplicat a tota peça mitjancera; l'entremès, el ball, la jacara, i altres fi de festa. La professora Pilar Espín ens explica que quan Juan de Agramont i Toledo va escriure uns entremesos més extensos i els va titular sainetes, altres autors van fer el mateix. En 1757, la nomenclatura, ja estava plenament acceptada en el teatre quan Ramón de la Cruz començà a compondre els seus. El nom de sainete fou cada vegada més empleat per a designar les mateixes peces breus $\mathrm{i}$ jocoses, encarregades d'acompanyar la comèdia dins del conjunt que constituïa la representació teatral completa. De llavors ençà, el sainete va prenent importància fins al punt que l'èxit d'una comèdia podia augmentar o disminuir segons l'acceptació que aquestes peces menudes tingueren en el públic (Espín 1987: 98-100).

Al País Valencià, entre els s. XVI-XVII trobem la presència de peces curtes en vers i dialogades, els diálogos. Aquestes peces recitades en valencià, són les que donaren el fonament als col loquis de temàtica satírica, de tipus i costums. En les darreries del s. XVIII, l'aparició de nous autors, amplificarien aquesta temàtica burlesca en política i religiosa. Aquests col loquis, molt apreciats i coneguts pel poble valencià, eren representats juntament amb el teatre en castellà.

No hi ha dubte, que l'aparició del sainet com a forma dramàtica típica del teatre escrit en valencià, es degué a la influència exercida pel sainete del set-cents i del col loqui autòcton (Sirera 1981: 27-29).

Els professors Sansano i Castaño, recordant paraules de Ricard Blasco, ens donen una definició de sainet en la que «l'hem d'entendre com una peça teatral, generalment breu, en prosa o vers, de caràcter jocós, la qual reflecteix la parla i els costums populars». Amb una trama argumental estructurada al voltant d'una única situació. La seua representació era destinada per amenitzar la representació d'una obra llarga, completant-la. Així, de vegades trobem el sainet al principi de l'espectacle, al final i inclús en l'intermedi (Sansano i Castaño 1997: 58). 
Sobre aquest terme, introduït en el s. XIX derivat del castellà, Josep Lluís Sirera ens fa una reflexió de la seua utilització generalitzada per a denominar les peces curtes teatrals valencianes. Ens explica com ha estat una denominació imposada al marge dels autors, tant per una crítica teatral castellanitzada com per la comoditat i la necessitat dels estudiosos teatrals a l'hora d'acollir aquest vocable, el qual, a més no sempre concordat amb els costums de l'època. Ens posa d'exemple a Eduard Escalante. En cap de les quaranta-set peces publicades dins de la col lecció Obras completas, l'autor utilitza el terme sainete/sainet, sinó el de pięa, juguete, comèdia, Zarzuela, cuadro, afegint la qualificació de bilingüe i o valenciano. Sirera afirma que aquest mot és incert alhora de ser utilitzat tant en castellà com en català.

Ens dóna a entendre que, dins de la definició que tenim del sainet hi ha bastant amplària com per permetre l'existència de diferents variants o subgrups individualitzats.

Es refereix al sainet com un gènere teatral que va desenvolupant-se i es mostrarà més permeable a les influències d'altres formulacions teatrals (Sirera 1994).

Els autors valencians noucentistes, seguint les línies marcades per una burgesia i una menestralia enriquida que accepta de bon grat el teatre culte castellà, faran del sainet el seu modus vivendi.

Aquest sainet serà de gènere realista pel que fa a espais i personatges. Els quals seran mostrats en escena parlant segons la classe social a la qual pertanyen i amb els accents corresponents a la seua localització. Representatiu tant de les tradicions urbanes com agràries, propugnant la no transgressió de la moral convencional social. En alguns casos explicitant la seua moralitat i la intencionalitat ètica. Aquesta intenció didàctica anirà constatant-se al llarg de la peça i inclús en diverses ocasions serà aclarida i repetida al final d'aquesta, en l'acomiadament dels actors al públic.

L'autor que esdevingué el model a seguir a partir de la Restauració fou Escalante. Les seues obres constitueixen un retaule de tipus populars valencians. Els quals adopten un esquema conformista amb el seu comportament moralitzant d'actitud immobilista. «Escalante, traslladarà els personatges del món rural a la ciutat situant-los en els barris populars del cap i casal, enfonsant-los en els conflictes tradicionals del gènere on sempre hi han finals feliços: els enamorats i els pares d'aquests, els forasters, el vell que vol a la jove i els obstacles a vèncer per arribar a un desenllaç precipitat $i$ senzill que aconsegueix el riure fàcil del públic» (Sales 2020: 96).

Sanchis Guarner ens remarca amb paraules de Ricard Blasco que l'èxit més gran d'Escalante consisteix a «haver sabut captar amb vivacitat les aspiracions d'una classe mitjana urbana en formació, la qual per sentir-se representada en escena, es va identificar amb les senzilles normes ètiques de l'autor» (Sanchis Guarner 1980a: 55). Altres autors com Joaquin Balader, José Ovara, Francisco Palanca i Roca, Antonio Roig i Civera, Manuel Barreda, coetanis d'Escalante no van tindre tanta repercussió encara que no manquen d'importància.

Aquest tipus de sainet de costums junt amb personatges que parlen una barreja de castellà valencianitzat o viceversa com a recurs còmic, per treure la rialla del públic serà la tendència formal 
i narrativa més utilitzada pels comediògrafs valencians. Aquesta manera de parlar mesclant les dues llengües a part de provocar les rialles del públic els permetia satiritzar la burgesia ascendent que deixava de parlar amb la llengua pròpia per pujar en l'escala social. Però açò, lluny d'induir el públic de preservar la llengua, el que va ocasionar va ser una disglòssia i la seua corrupció (Blasco 1984: 54).

\section{E1 teatre Russafa. 1890/1891 una temporada teatral fructífera}

Des de finals dels anys setanta, el teatre Russafa havia passat a ser propietat d'Antonio Díaz Torres (1833-1889). Casat amb Joaquina Cortés Aliaga (1834-1909), a qui a la mort del seu marit l'11 de febrer de 1889 d'una malaltia coronaria a l'edat de 56 anys, se li fou adjudicada la propietat del coliseu. Llavors, el seu germà polític Rafael Díaz, s’ocupava de les feines de gerent del teatre.

Sabem per la premsa, que la família Díaz sempre va estar compromesa amb els més desafavorits de la societat. Donava suport de manera altruista a les desgràcies personals. El teatre Russafa sempre tenia les seues portes obertes per a donar representacions de benefici, ajudant tota mena de causes (Anònim 1889: 2). Tenim també constància per cartes personals, dels préstecs que feia als actors i a les companyies que actuaven al seu teatre, favors que després continuaria fent el seu germà Rafael (Fons Culla).

Respecte al teatre en valencià, el Russafa durant el s. XIX va ser un dels coliseus que més suport va donar als autors i companyies de teatre en llengua vernacla. En un anunci emès pel diari Las Provincias en 1878, es fa palès quan l'empresa del teatre convida els autors teatrals valencians a presentar les seues noves produccions al mateix coliseu amb la intenció de ser estrenades:

\footnotetext{
La empresa del teatro-café de la calle de Ruzafa deseosa de contribuir al engrandecimiento de la literatura patria estimulando a los autores dramáticos de esta ciudad, ha hecho un llamamiento a los mismos para que se dignen a presentar las obras que produzcan a dicho teatro con objeto de ponerlas en escena, siempre que reunan las condiciones convenientes y puedan representarse con los elementos de que dispone la requerida empresa (Anònim 1878: 2).
}

Cinc de les obres ací tractades duen en la portada, juntament amb el seu títol, la rúbrica del propietari del teatre Russafa. Característica que ens hem trobat en moltes obres del llegat de la família Culla. La qual cosa ens fa suposar que havien sigut comprades als seus autors, passant així a formar part de l'arxiu del teatre on han romàs fins ara.

Una de les obres, la qual ens ha aparegut sense nom d'autor i sense cap signatura, és la revista bilingüe en un acte Valencia. La seua autoria l'hem poguda esbrinar gràcies a una recerca exhaustiva pels diaris de l'època.

Una de les obres, Consumos y Consumeros, va ser estrenada en la temporada teatral de Pasqua de 1888. Les altres cinc, Lo qu'importa es relluir, Un barber de contrabando, Un incrèdul, Cachet i Colom i Valencia, foren estrenades en la temporada teatral d'hivern 1890/1891. Temporada que començà el dissabte 20 de setembre en la sessió de nit. 
A causa de l'estat sanitari que patia la ciutat de València aquell any -1890-, per l'epidèmia de la còlera, el primer actor i director de la companyia contractada, Pere Riutort i la primera actriu Pilar Clemente, no havien pogut arribar a la ciutat a complir amb l'inici de la temporada. L'empresa del Russafa, no volgué retardar més la inauguració de la temporada i la companyia còmica valenciana va estar dirigida pels actors Juan Colom i Salvador Soler, qui van ser els encarregats de dur a terme aquesta tasca (Anònim 1890: 2).

L'elenc artístic que llavors la formaven eren les actrius: Matilde Ruiz de Galván, Antonia Colom i Sales, Aurora Castillo, Elena Rodriguez, Amparo Pardinillas, Josefa Marí de Soler, Sra. Irurzum i els actors: Juan Colom i Sales, Salvador Soler, Manuel Taberner, Federico Augusto, Félix Guillen, José Martí, José Rausell, Sr. Riba.

Riutort i Clemente, acabarien rescindint el seu contracte amb el Russafa. Llavors, va ser el primer actor i director Eduardo Pérez Cachet qui fou ajornalat com a director de la companyia (Anònim 1890a: 2).

Les obres que eixa nit es van posar en cartell foren, la comèdia en tres actes en vers de Miguel Echegaray Meterse a redentor, la qual podem trobar en el fons Culla amb la sig. 1612 i Una broma de sabó, apropòsit bilingüe en 1 acte en vers de Rafael $\mathrm{M}^{\mathrm{a}}$ Liern.

La temporada va ser molt fructífera per la varietat d'estrenes que hi va haver, sobretot de peces escrites en llengua vernacla. Conforme l'Almanaque de Las provincias, es van estrenar 34 obres, mal que segons la seua opinió, no va ser tanta la qualitat com la quantitat. Referent a les peces teatrals valencianes, qualificava de lamentable l'actitud de l'empresa del teatre Russafa. Trobava imperdonable que, tant els actors encarregats de dirigir les obres com l'empresa, no exigiren un mínim de qualitat en les obres que posaven en escena. L'acceptació d'obres d'autors novells sense experiència per donar-los l'oportunitat de presentar-se al públic era un punt a favor que sempre havia caracteritzat a aquest teatre, però no haurien de fer el mateix amb aquells que no mostren cap noció d'escriptura teatral (Anònim 1892: 205).

\footnotetext{
Hay quien en su ignorancia cree que para hacer aceptable una comedia valenciana, basta poner en boca de los personajes cuatro chocarrerías, acompañadas de algún chiste de mal género. Sólo así se explican los engendros que para mengua y baldón del género valenciano se han visto en la escena de este teatro (Anònim 1892a: 206).
}

En les mateixes pàgines se'ns mostra un llistat de les obres valencianes que van ser estrenades aquella temporada i ací és on trobem cinc de les peces que hem presentat en aquest treball: Romeu, Fucbint de l'anguila, Valencia, El tesor de la sultana, ${ }^{1}$ El canari, Sixtet o les criailles, Un incrèdul, Un barber de contrabando, Lo que importa es relluir, Faena-fuig, Bous de cartó, El que menja de baldraga, Sento pega, Cachety Colom y Tot per Quiquet.

1 El tesor de la sultana de José Campos Marté i música de Ramón Gorgé, va ser estrenada el 8 de setembre de 1890 al Teatre Circo d'Alacant i no al Russafa, que sí va ser representada per primera vegada a València. És un apropòsit líric valencià escrit per a Amparo Pardinillas i Manolo Taberner. Fons Culla sig. 945/2500. 


\section{Les obres rescatades}

Quant a les obres que hem presentat, dir que totes elles estan escrites dins els cànons d'escriptura que seguien els sainets de l'època. Podem apreciar que són peces de costums urbanes, on el valencià queda reservat per a la get de classe mitjana, els llauradors i les criades, i el castellà pels forasters i els personatges de les classes més altes.

El llenguatge utilitzat és el denominat valencià central o apitxat. Variant dialectal del català corresponent a la parla de València capital i les comarques de l'Horta, Camp de Morvedre, Camp de Túria i la major part de la Ribera Alta. Trobem arcaismes i castellanismes, interferències lèxiques, sintàctiques i morfològiques. Respecte a la morfologia verbal s'aprecia l'ús del pretèrit perfecte simple, característica del valencià apitxat. Però també parèmies i algunes frases fetes. Expressions que encara avui podem sentir dir a la gent més gran de pobles de la rodalia del cap i casal: Guapo!, referint-se a fer nosa alguna cosa; Morral, quan algú té lbarra; Moixa, falsa, enganyadora; Churra, ací es refereix a les xicones que venien des de la comarca dels Serrans o Terol a treballar com minyones a la ciutat de València; Guilopo, al País Valencià té el sentit d'entremaliat; això són dotoreries, com xafarderies; Me té frechit, estar tip; pegar en la capsana, referint-se al pegar al cap; corruco, arrugat; furri, quan és de mala qualitat; Lladriola, guardiola; ves i fregat les cames, per a despatxar algú de males maneres; tirar-se un rotllo al pap, menjar un poc; fer figa, fallar alguna cosa; portar pasó, endur-se una reprimenda, etc.

Quatre de les peces ací tractades van ser estrenades en una funció de benefici. Els actors i les actrius, buscaven lluir-se el dia del seu benefici amb l'estrena d'una peça fora del seu repertori habitual. Llavors, solien fer una petició als comediògrafs per a que els escrigueren en exclusivitat una obra per a l'ocasió. Sols una d'aquestes quatre peces a les quals fem referència, Cachet y Colom, va ser escrita en exclusivitat $\mathrm{i}$ amb aquesta finalitat. Ho podem corroborar en el seu manuscrit on l'autor Juan Colom escriu: «Apropósito bilingüe en un acto y en prosa, escrito expresamente para el beneficio del primer actor D. Eduardo Cachet». ${ }^{2}$

A raó de ser escrites amb eixa exclusivitat, moltes d'aquest tipus d'obres de benefici s'han perdut.

En el cas de Lo qu'importa es relluir i Un incrèdul, que també van ser estrenades en una funció de benefici, comprovem que no consta cap dedicatòria per part dels autors. Sí que podem llegir en el repartiment, al costat de cada personatge escrit com anotació, els noms dels actors i actrius de la companyia que participaren en la funció. Observem ací, que cap de les dues actrius beneficiades eixes nits, Matilde Ruiz de Galvan i Josefa Marí, van actuar en les estrenes. Les dues actrius eren castellanes i quan participaven en sainets ho feien representant papers castellans. En Cachety Colom, Josefa Marí interpreta a Emilia, muller de Colom, personatge castellà-parlant.

2 El nom complet d'aquest actor era Eduardo Pérez Cachet, però era conegut per Eduardo Cachet. 
Referent a l'estrena de la revista Valencia, va ser una casualitat que aparegués en cartell la nit de benefici del comptador del teatre. L'obra, s'hauria d'haver posat en escena una setmana abans, però el no tenir a punt la construcció del decorat fou la causa del seu retard (Anònim 1891: 2).

Valencia, és l'única de les sis obres les quals presentem que no ha estat mencionada en el catàleg de Guastavino. Aquesta peça sols l'hem vista citada a l'Almanaque de las Provincias.

L'obra és una revista musical, gènere teatral que va aparèixer en 1864 on la seua temàtica consistia a donar un lleuger repàs als esdeveniments més assenyalats ocorreguts en el transcurs de l'any.

Segons Montijano, va ser l'escriptor andalús José $\mathrm{M}^{\mathrm{a}}$ Gutiérrez de Alba, qui en un viatge a París va tindre l'oportunitat de presenciar un vodevil titulat 1841-1941. La trama, gairebé sense intriga ni embolics amorós, relatat amb personificacions al legòriques, reflectia com seria la capital francesa dintre de cent anys. Aquest fet féu que l'autor espanyol iniciés una sèrie d'obres com 1864-1865, 1866-1867, amb uns arguments on apareixien convertits en personatges, La Loteria, La Moda, Las Calles, Los Periódicos, etc.; Tots ells reencarnats en senyoretes amb un físic espectacular que atreien l'atenció del públic masculí. L'espectacle era completat amb l'animació d'algun còmic contant uns quants acudits. Autors com Guillermo Perrín, Miguel de Palacios, Francisco Arderius, Carlos Arniches, Salvador $\mathrm{M}^{\mathrm{a}}$ Granés, escriviren reconegudes revistes d'aquest gènere.

En els seus estudis, Montijano afirma que la revista tal com avui l'entenem, no és un gènere pur, sinó que ha anat evolucionant. Està influenciada pel sainet -del que pren el folklore urbà i regional a més dels seus tipus i arguments-, del vodevil -del que còpia clàssiques situacions i personatges teatrals-, de la sarsuela, el music-hall, el cabaret, l'opereta i els cuplets -dels que pren els ritmes i l'atractiu eròtic de les ballarines, la juxtaposició d'escenes, la sàtira i els acudits-, influències totes elles que han anat confeccionant el gènere (Montijano 2013: 26-27).

El joguet en vers Un incrèdul, escrita en vers, és l'única d'aquestes sis peces que no és bilingüe, cap dels seus personatges parla castellà. Les acotacions, llevat de la descripció de l'escenografia, sí que apareixen escrites en castellà. És la més breu en nombre d'escenes i el seu text no presenta cap esborrall, cosa que sí trobem en les altres. Les eliminacions de text, marcades pel director d'escena, se solen fer per poder adequar els diàlegs al temps de representació quan aquests són massa llargs o s'aprecia una pèrdua de ritme.

\section{Consumos y Consumeros}

Peça bilingüe en un acte en vers d'Eduardo Escalante Feo (1858-1921).

Estrenada el divendres 4 de maig de 1888 al teatre Russafa de València. El cartell, aquella nit, estava format per la comèdia en tres actes La primera nit de maig de Rafael Torromé, i la peça curta Consumos y Consumeros (Anònim 1888: 4). 
D'aquesta obra, es conserven al llegat de la família Culla, tres còpies manuscrites amb el nom d'autor, sig. 596/981. En la portada dels manuscrits podem apreciar la rúbrica d'Antonio Díaz, aleshores propietari del teatre Russafa.

És possible que aquesta peça haguera estat editada. Considerant que en l'edició de la comèdia bilingüe, Cada ú de son temple del mateix autor, editada per l'Antiga llibreria de Juan Mariana i Sanz en 1890, apareix aquest títol junt altres obres ja editades d'Escalante Feo.

Consumos y Consumeros, la trobem citada en l'Almanaque de Las Provincias on assenyala que la seua estrena fou en la temporada de primavera de 1888 (Anònim 1889a: 134).

Eixa temporada teatral, corresponent a la de Pasqua, va ser contractada una companyia dramàtica castellana-valenciana.

La companyia estava formada pel primer actor i director Francisco Troyano. A més de les actrius: Josefa Marí, Joaquina March, Amparo Pardinillas, Consuelo Peris, Dolores Simó i Cristina Talens. Junt els actors: Enrique Alcácer, José Contreras, Emilio Dubal, Juan García, Alfredo Paredes, José Rausell, Bautista Rodriguez, Salvador Soler i Julian Valero i els apuntadors: Enrique Bartual, Vicente López i Vicente Morales.

El diari de Las Provincias, anunciava el repertori de la companyia i donava un avanç de les peces valencianes a estrenar. Tomás el ferreret, El tio Piulo, Cada ú en sa casa i Els Consumeros. Amb Els Consumeros, donem per segur que venien a referir-se a l'obra d'Escalante Feo, Consumos y Consumeros (Anònim 1888a: 1).

L'obra, escrita en un acte, està distribuïda en deu escenes i una final. Va ser composta per a dotze personatges; 4 femenins, 7 masculins i 1 xiquet. Com que no sabem quins actors participaren en l'estrena, junt amb la llista dels personatges hem inclòs el nom dels actors i actrius que van actuar en la reposició de l'obra el 15 de març de 1891. Els artistes són els que van actuar en la temporada d'hivern, referida anteriorment -1890/1891-. Aquest llistat d'actors i actrius consta en un dels manuscrits trobats al teatre.

$\begin{array}{ll}\text { Carmela - } & \text { Aurora Castillo } \\ \text { Macaria - } & \text { Amparo Pardinillas } \\ \text { Marieta - } & \text { Elena Rodriguez } \\ \text { Jin-ni - } & \text { ? } \\ \text { Carlets - } & \text { Salvador Soler } \\ \text { Quico- (guarda 10 del resguard) - } & \text { Adrian } \\ \text { Llorens (guarda 20 del resguard) - } & \text { Federico Augusto } \\ \text { Tofol - } & \text { Manolo Taberner } \\ \text { Miquel - } & \text { José Rausell } \\ \text { Pere - } & \text { José Martí } \\ \text { Vicent (Guarda municipal)- } & \text { Minguez } \\ \text { Nelet- (Xiquet)- } & \\ \text { Homes i ixiquets que no parlen. } & \end{array}$


L'obra representa una crítica a l'impost de consums establert en l'Espanya noucentista. A les portes de la ciutat de València hi havia casetes, burot-fielato-, on cobraven per l'entrada o eixida de productes bàsics anomenats coses de menjar, beure i cremar, com la farina, oli, vi, carbó.

Ací, l'autor, ajudant-se en uns personatges que pertanyen al proletariat, reflecteix la realitat social de l'època. Parodia l'abús que els guardes del burot perpetraven en intentar quedar-se part de la mercaderia de les persones que per allí passaven. Al mateix temps mostra la pilleria dels matuters i matuteres.

L'escenografia, tal com apunta el llibret de l'obra, representa l'espai corresponent des de la placeta del carrer de Llíria al pont nou de Sant Josep en la ciutat de València. A l'esquerra en segon terme està la caseta o burot de Consums, a la porta d'aquesta hi ha una bàscula i dos tamborets. A la dreta del fòrum trobem un piló o banquet figurant estar situat a l'extrem o baixada del pont.

En la primera escena l'autor ens presenta els dos guardes del burot i un matuter, Carlets, que aguaita pel fòrum. Ací pel diàleg que mantenen els dos guardes i les frases que Carlets dedica al públic, ja se'ns deixa ben dibuixat quin és l'argument de l'obra, i així mateix, ens mostra la personalitat i el caràcter de Quico - guarda $1^{\circ}$-, que serà el personatge principal. No per ser l'heroi, sinó per ser el personatge que més presència cobra al llarg de l'obra.

Les escenes segueixen una mateixa tendència narrativa. Durant aquestes, els personatges, menys els dos guardes que sempre romandran a escena, van entrant i eixint. Els matuters volen passar matute, els guardes, sobre tot Quico, de malnom Tremendo - qui es creu més llest que ningú i que resulta ser un personatge odiat pels matuters-, els fan xantatge i es queden part de la mercaderia. Dels dotze personatges sols hi ha un que parla castellà i amb accent estranger, els altres parlen un valencià castellanitzat ple de barbarismes. Per la seua part, les acotacions en el text apareixen escrites en castellà. Les escenes mostren situacions còmiques entre el recel dels guardes i la pilleria dels vianants.

En la tercera escena, el personatge de Pere, arriba a la porta del burot i els guardes li donen l'alt:

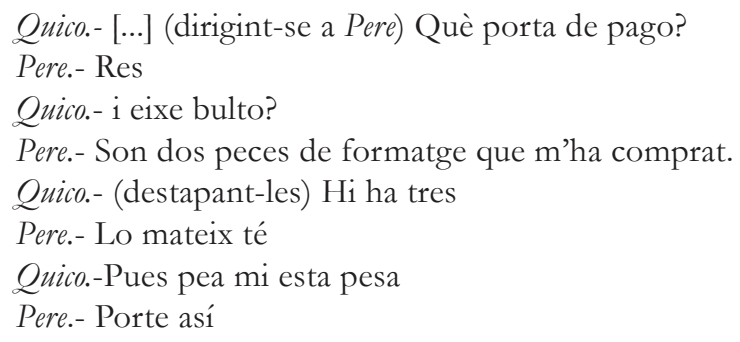

Després d'una estira-i-arronsa, Pere ha de pagar pel tercer formatge i com no du diners, el deixa en dipòsit, mentre va i torna a pagar. Els dos guardes es queden mirant la peça de formatge. 


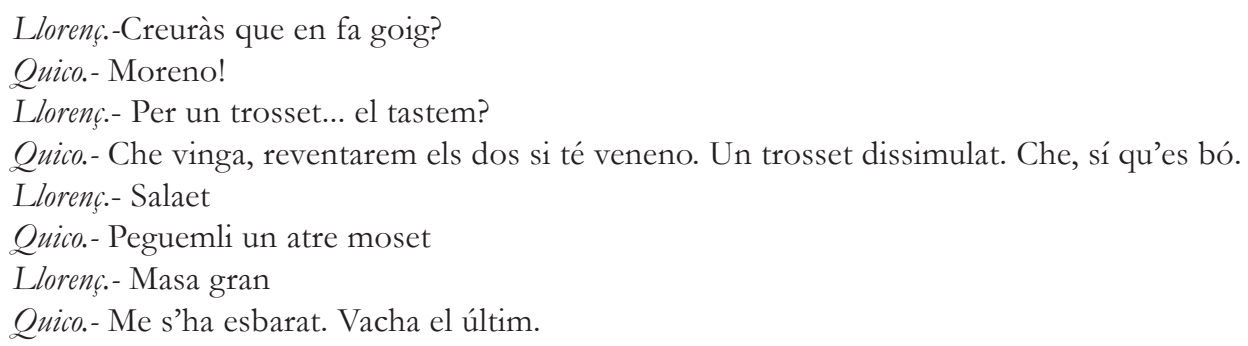

Fill d'Eduard Escalante, Escalante Feo va continuar amb la tradició literària escrivint diversos sainets i sarsueles. En 1878 va escriure el miracle El incrèdul convertit. En el mes d'octubre de 1908, dins de la temporada teatral 1908/1909, el teatre Russafa fou testimoni de tres de les seues estrenes. L'esbós líric dramàtic en 1 acte i 4 quadres, Fiestas y Amores. Llibret que Escalante Feo escriu junt amb Francisco Morán i el mestre compositor Manuel Izquierdo. Eixe mateix mes estrena la sarsuela còmica dramàtica El Roder, en 1 acte i en vers la qual està musicada pel mestre Salvador Giner. I en novembre, estrena la sarsuela fantàstica en 2 actes i 6 quadres, inspirada en el poema romàntic $L a$ silfide del acueducto de Juan Arolas, Porta-Coeli, i música del mestre Vicente Peydrò amb qui formaria un tàndem de creació lírica valenciana d'èxit. Aquesta sarsuela va fer un total de 50 reproduccions eixa temporada.

En el llegat de Rafael Culla es conserven els següents joguets, comèdies i sarsueles: Del porrat de Sant Antoni a les torres de Serrans (1887) sig.551; Mariquita la estanquera (1889) sig. 2214, Cada ú de son temple (1889) sig. 135/410/2114; Un alcalde de barrio (1897) sig. 2172; Mil duros y tartaneta (1896) sig. 870. Les sarsueles amb música de Vicente Peydró Quintos y reganchaors (1889) sig. 2209; Les barraques (1899) sig. 2548/2727; Elpresidiari (1902) sig. 1125; Junt a Ricardo Flores i música de Chavarri i José $\mathrm{M}^{\mathrm{a}}$ Lorente, Amor i Patria (1896) sig. 1777 (1921) Sig. 2515.

\section{Lo qu'importa és relluir}

Esbós bilingüe en 1 acte en vers de José Campos Marté (m.1906)

Estrenada el dijous 27 de novembre de 1890 en el benefici de la primera actriu Matilde Ruiz de Galvan al teatre Russafa de València.

El programa eixa nit el componien el drama en 3 actes i en prosa d'Isidoro Gil (1841) La cisterna de Albi, la qual trobem al llegat Culla amb la sig. 739/2719; el drama en 1 acte en vers d'Antonio Hurtado (1867), La voz. del corazón, obra que també podem veure al llegat amb la sig. 162, i tancant l'espectacle l'estrena de l'esbós de Campos Marté (Anònim, 1890b: 2).

En el llegat de Rafael Culla podem trobar aquesta peça amb la sig. 2226. Es conserven dues còpies manuscrites, una d'elles és la corresponent a l'apuntador. En la portada dels manuscrits, podem apreciar la rúbrica de Joaquina Cortes, aleshores viuda d'Antonio Díaz i propietària del teatre. 
La peça es presenta en acte únic, distribuït en divuit escenes i una final composta per a nou personatges, 7 masculins i 2 femenins, els quals queden descrits per l'autor de la següent manera: Fani, senyoreta elegant, vesteix primer matiné i després trage de recibo (amb aquesta expressió l'autor vol dir que vesteix elegantment); $\mathrm{D}^{\mathrm{a}}$. Pura, viuda de tres marits; Don Pasqual, senyor de poble, fill de llauradors rics, de 50 anys d'edat, no du ni bigot ni patilles. Vesteix vestit i després frac; El tio Toni, llaurador de 75 anys, molt alegre. Vesteix espardenyes, calçot curt i armilla de pana blau, faixa morada en manegues de camisa, mocador negre al cap i du una vara en la mà; Don Gregorio, de 40 anys, diputat. Du barret de copa i patilles; Ernesto, jove elegant; Tofolet, quinto de cavalleria, du gorra de soldat al cap; El marqués, de 50 anys, du una levita passada de dalt a baix, coll de camisa alt, guants, barret de copa i patilla curta. Va molt estirat; Diversos personatges femenins i masculins de figurants.

El repartiment dels personatges dins de la companyia el dia de la seua estrena era el següent:

$\begin{array}{ll}\text { Fani- } & \text { Elena Rodriguez } \\ D^{a} \text {.Pura- } & \text { Amparo Pardinillas } \\ \text { Don Pascual- } & \text { Manolo Taberner } \\ \text { El tio Toni- } & \text { Salvador Soler } \\ \text { Don Gregorio- } & \text { José Rausell } \\ \text { Ernesto- } & \text { José Martí } \\ \text { Tofolet- } & \text { Félix Guillen } \\ \text { El marqués- } & \text { Federico Augusto } \\ \text { Un lacayo (vesteix lliurea)- } & \text { Minguez }\end{array}$

Escenografia descrita per l'autor: L'acció transcorre a Madrid. Lola apareix molt elegant en una sala on hi ha consoles amb tapes de marbre, canelobres i un piano. Al fòrum una porta gran la qual en obrir-se -al seu temps- es veurà un saló amb una llum d'aranya encesa. En les últimes caixes hi haurà portes; la de la dreta de l'actor serà d'entrada i l'altra semblarà conduir a les cambres interiors. Una porta també en primer terme a l'esquerra. El piano pot estar en primer terme a la dreta.

En aquesta peça podem veure ja en la descripció de la sala i els elements que la complimenten que pertany a una casa acabalada. En la primera escena apareixen dos personatges que amb els seus diàlegs en un castellà cuidat ens compten el motiu principal de l'argument de l'obra: l'enllaç de dos joves i l'impediment que hi ha per assolir-se degut a la diferència de classe. A mesura que van dialogant ens van presentant els personatges que conformaran la trama, donant-nos a entendre com són. Un pare llaurador, viudo i ric amb una filla compromesa amb un jove aristòcrata fill d'un diputat que no veu bé eixe amor. El personatge clau que no és presentat apareix de sobte en l'escena sisena. Aquest personatge, el tio Toni, ve de València, vist de llaurador, parla valencià i quan intenta parlar castellà ho fa amb molta deficiència. És menyspreat per les seues maneres rústiques, fins i tot pel criat de la casa. Els personatges de l'aristocràcia se'ns mostren ridiculitzats, com observem amb el nom del marquès, Marqués del Pozo Ciego y Jarama del Ripio. El pare del nuvi, Gregorio, que 
ara és diputat resultarà i eixirà a la llum en el seu moment, que prové de família de pocs recursos econòmics. L'autor ens retrata les aparences adoptades en un personatge que renega del seu passat i que és despectiu amb aquells que creu inferiors. En l'escena onzena, Pascual, fart de sentir-se menyspreat pel pare del nuvi mostra la seua dignitat i planta cara a eixa aristocràcia cursi i postissa: «Esta usted fresco! ¿Por qu'es mi genio algo burdo, piensa que soy tan palurdo que no sé lo que me pesco? [...] ¿y a qué tanta altaneria ? si ustedes tienen blasones, yo en cambio tengo doblones, y oros son triunfos hoy dia»

En l'escena divuitena, arriba el punt culminant i el desenllaç de l'argument de la mà del personatge de Pascual. Quan Gregorio els diu salvatges, referint-se al tio Toni i a el seu net Tofolet: Pascual contesta: «Alto allà, qu'al hermano de mi madre nadie le ofende en mi casa [...] esa afrenta no la sufro yo de nadie [...] no paso por ese ultratge». L'obra esdevé amb un final feliç pels nuvis i un vers al públic per part del tio Toni:

\footnotetext{
Fruita del temps es pasar un quídam por gran señor la fanfàrria es de rigor, la gran cuestió figurar.

Yo vaig, pues, a demostrar que sé també relluir gastant chapes, y cal dir que no em doldran els dinés, si es que me animen vostès fent el favor de aplaudir.
}

\section{Un barber de contrabando}

Sainet bilingüe original de José Campos Marté (m.1906)

Estrenat el dilluns 29 de desembre de 1890 al teatre Russafa de València. Es conserven al llegat Culla amb la sig. 1451, dues còpies manuscrites d'aquesta obra. Una d'elles correspon a la part de l'apuntador.

El programa anunciat la nit de la seua estrena era la comèdia en 3 actes en prosa La posada de Lucas d'Eusebio Blasco (1882), la qual trobem al llegat amb la sig. 403, i tancava l'espectacle l'estrena del sainet de Campos Marté (Anònim 1890c: 1). La peça fou enregistrada en el registre civil de la ciutat el dia 8 de desembre de 1890. En la portada del manuscrit es pot veure la rúbrica de Joaquina Cortés.

Aquest sainet està estructurat en un acte, que a la vegada està distribuït en catorze escenes i una última. Està escrit per a cinc personatges, 1 femení i 4 masculins. Aquests són els següents: Pepeta, sirventa llauradora; Blay, llaurador i orxater; Felipe, andalús, xicot aprenent de barberia; Don Apolonio, vell; Un vigilant, no parla. 
El repartiment entre els artistes de la companyia fou el següent:

$\begin{array}{ll}\text { Pepeta - } & \text { Elena Rodríguez } \\ \text { Blay - } & \text { Salvador Soler } \\ \text { Felipe - } & \text { Sr. Andújar } \\ \text { Don Apolonio - } & \text { Manolo Taberner } \\ \text { Un vigilant que no parla }\end{array}$

Escenografia descrita per l'autor: Interior d'una barberia en el baix d'un pis. Una porta al fòrum per la que es veu el carrer i altra a l'esquerra de l'actor.

L'autor ens presenta una comèdia d'embolic amb personatges d'estereotip social. El tipus de foraster apareix ací encarnat en el personatge de Felipe. Aquest, parla castellà amb accent andalús. En el soliloqui de l'escena inicial, Felipe mentre ens va descrivint tots els personatges que aniran apareixent en les següents escenes, trau a la llum les seues intencions dins l'obra i ens deixa clar el menyspreu i animadversió que sent pels valencians: «Los valencianos a mi me hacen poquíssima gracia».

L'espectador pot intuir fàcilment que es tracta d'un pillo i un embolicador. El seu objectiu és fer que Pepeta i Blay trenquen el seu enllaç per casar-se amb ella. Una vegada casat, podrà vendre unes terretes que Pepeta posseeix i així poder tornar-se'n cap a la seua terra, Andalusia.

En l'escena set, Blay i Felipe, tenen una conversa de poder territorial. L'un és vanaglòria de tindre terres i casa de camp en Andalusia i l'altre de posseir garrofers, granaders i una gran barraca, tota fanfarroneria. Felipe farà creure a Blay que l'amo de Pepeta, Don Apolonio vol casar-se amb ella, i a Pepeta que Blay té intencions amb una altra xicota. El desenllaç vindrà en l'escena tretze quan es desfà l'embolic. En l'escena catorze Felipe pagarà per la seua tramoia. De cara al públic, Blay, content amb la futura boda amb Pepeta, recita també uns versos finals demanant els aplaudiments del públic:

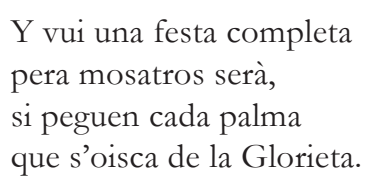

Campos Marté deixà un corpus prou extens d'obres en un acte, sainets, joguets, apropòsits, esbossos, comèdies i sarsueles. A continuació citem les que consten al llegat de Rafael Culla: La camisa de color (1890) sig. 1976; El retrato de la abuela, sig. 2042; Apuros d'un dovensà (1893) sig. 2142/2570; Eu pensaré o el millor ball el fandango (1894) sig. 2383; Milord Quico (1887) sig. 2528. Amb música de Rigoberto Cortina: Nelo Testes, sig. 2541; Un flamenco d'Alboraya (1885) sig. 2245; Trompa, petenero i màrtir! (1887) sig. 1522/2572; Coralito (1888) sig.754/672/2320/2369/2584; Un granerer en casaca (1888) sig. 626/2221. Amb música de Vicente Peydró: El chuí final (1887) sig. 25/584/2178/2552; El gallet de favareta (1896) sig. 627; Milord Quico (1887) sig. 2528. Amb música de José $\mathrm{M}^{\mathrm{a}}$ Llorente i Vicente Peydró: Dos almas en pena, sig. 2557. Amb música de José $\mathrm{M}^{\mathrm{a}}$ Llorente: El fill de la marquesa, 
sig. 2514; El salonet de les flors, sig. 2468/2587; La boda de Valentín, sig. 2393; Un baró de campanetes o la festa aigua (1897) sig. 1482/2465. Amb música de Vicente Lleó: Un casament del dimoni (1894) sig. 313/954/2530. Amb música de Ramón Gorjé: El tesor de la sultana (1890) sig. 945/2500.

\section{Un incrèdul}

Joguet en 1 acte en vers, original d'Estanislao Mañez Vidal (1844-1914)

Estrenat el divendres 12 de desembre de 1890 en el benefici de l'actriu Josefa Marí de Soler al teatre Russafa de València.

La nit de l'estrena, el programa estava compost pel melodrama en cinc actes i un pròleg Maria menotti o la loca de los Alpes, d'Alfredo Moreno Gil, que podem trobar al llegat Culla amb la sig. 330/549. Tancava l'espectacle l'estrena del joguet en un acte de Mañez Vidal (Anònim 1890d: 2). D'aquest joguet, al llegat de Rafael Culla es conserven dues còpies manuscrites amb la sig. 1450. Aquesta obra fou esmentada al govern civil de la ciutat el 8 de desembre de 1890. En la portada dels manuscrits es pot apreciar la rúbrica de Joaquina Cortés.

L'obra es presenta en un acte únic i es divideix en tretze escenes i una última. Escrita per a vuit personatges, 2 femenins i 6 masculins. El repartiment, la nit de la seua estrena, va ser el següent:

$\begin{array}{ll}\text { Pelegrina - } & \text { Amparo Pardinillas } \\ \text { Encarnasión - } & \text { Elena Rodriguez } \\ \text { Chimo - } & \text { Manolo Taberner } \\ \text { Salvaor - } & \text { Salvador Soler } \\ \text { Rafel - } & \text { José Martí } \\ \text { Conspirador } 1^{\circ}- & \text { Federico Augusto } \\ \text { Conspirador } 2^{\circ}- & \text { José Rausell } \\ \text { Un municipal - } & \text { Félix Guillen }\end{array}$

Escenografia descrita per l'autor: L'escena representa una casa decentment moblada. Porta al fòrum i lateral.

L'argument tracta sobre un tema social d'actualitat com era la malaltia de la còlera en la València d'aquell temps. En la descripció escènica que fa l'autor, ens mostra una família modesta. El comediògraf, amb el personatge de Ximo retrata a un home que no creu en la ciència ni amb els metges. Pensa que la còlera que està envaint la ciutat no és real.

En la primera escena trobem a Ximo qui, mitjançant la recitació d'un monòleg, ens diu allò que està passant a la ciutat, qui és ell i quina opinió té dels metges i de la situació. 
Els altres personatges aniran entrant i presentant-se en les escenes posteriors. Peregrina i Encarnasión, dona i filla de Ximo, que no dubten de la situació que està tenint a València; Rafel, el veí que se sent molt espantat i pateix per sa tia que està malalta; Salvaor, nebot de Peregrina, un malfaener i un poca-solta. Ximo, junt els conspiradors traça un pla de revolta contra els metges, que consisteix a no deixar-los acostar a sa casa, donant el moment, i espantar-los a pedrades. En l'escena tretze apareix un municipal que es donarà l'ordre d'eixir de la casa perquè la finca on viuen està infectada pel còlera.

Al final de l'obra Ximo s'acomiada del públic donant un consell:

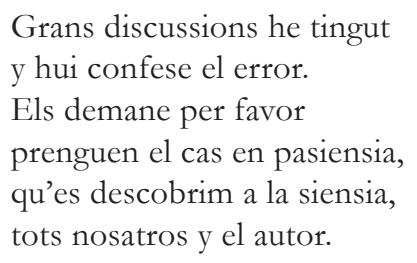

Mañez Vidal fou un autor dramàtic de poesia fàcil i graciosa, periodista de publicacions humorístiques i intèrpret de guitarra i bandúrria. Al llegat de la família Culla hem trobat algunes de les seues obres més exitoses: ElMarsellet (1886) sig. 631; El häbit no fa el frare (1883) sig. 463/1444; Bous sense pa (1888) sig. 963.

\section{Cachet y Colom}

Apropòsit bilingüe en un acte, de Juan Colom i Sales (1852-1917)

Estrenat el divendres 30 de gener de 1891 al teatre Russafa de València. Escrit expressament pel benefici del primer actor Eduardo Cachet -així consta en el llibret de l'obra.

El programa la nit de l'estrena estava compost pel drama popular en quatre actes en vers Diego Corrientes de José $\mathrm{M}^{\mathrm{a}}$ Gutierrez de Alba (1880), que podem trobar al llegat Culla amb la sig. 1828. Continuava l'estrena de l'apropòsit de Cahet $i$ Colom i per a finalitzar la comèdia en un acte Basta de suegros, d'Eduardo Lustono (1875), la qual també la trobem al llegat amb la sig. 1593 (Anònim 1891a: 2).

Al llegat de la família Culla, sols es conserva una còpia manuscrita d'aquesta peça, amb la sig. 982. A la portada del seu manuscrit, podem apreciar la rúbrica de la propietària del teatre, Joaquina Cortés, així com la data del seu registre al govern civil de la capital, el 23 de gener de 1891.

L'obra està composta per un acte únic, dividit en dinou escenes i una última. Escrita per a nou personatges, 3 femenins i 6 masculins.

El repartiment dels personatges entre els artistes el dia de l'estrena fou el següent:

$$
\begin{array}{lc}
\text { Júlia- } & \text { Antonia Colom } \\
\text { Emilia - } & \text { Josefa Marí }
\end{array}
$$




$\begin{array}{ll}\text { Neleta }- & \text { Aurora Castillo } \\ \text { Cachet- } & \text { Eduardo P.Cachet } \\ \text { Colom - } & \text { Juan Colom } \\ \text { Máximo - } & \text { Manolo Taberner } \\ \text { Un autor - } & \text { Federico Augusto } \\ \text { Un femater - } & \text { Félix Guillen } \\ \text { Un perruquer- } & \text { Sr. Llorens }\end{array}$

Escenografia descrita per l'autor: Sala decentment moblada, porta al fòrum i dues als costats dret i esquerre, primer i tercer terme. En el segon terme dreta, taula escriptori.

La peça és una comèdia d'embolic, el teatre dut dins del teatre, on l'acció es desenvolupa en la casa de Colom. El personatge de Colom, representa un comediògraf compromès en escriure un apropòsit pel benefici del seu amic actor, Cachet. De moment, Colom, no té cap idea concreta de com ha de ser l'obreta. A la casa acudeix Cachet, demanant-li ajuda en la preparació del paper de Peret, de l'obra El sant del agüelo, del mateix Colom. Cachet, és castellà-parlant i vol representar un paper valencià per fer una gràcia al públic i agrair així els aplaudiments que sempre li han dedicat. Per altra banda apareix Júlia, muller de Cachet, qui acudeix a casa de Colom amb la intenció de preparar l'obra La fe perdida. Per la seua banda, Máximo, sogre de Colom, pensa que Júlia és l'amant del seu gendre. I de tot aquest embrollament sorgirà la paròdia teatral que donarà la idea a l'autor. Complirà amb ella doncs, el compromís que tenia adquirit pel benefici del seu amic. Una història fictícia convertida en història real.

En la primera escena Neleta, la criada i Máximo, sogre de Colom, donen pas a l'embolic amb els seus comentaris:

\footnotetext{
Máxim.- ¿No has comprendido que esa mujer que viene alguna tardes es un lio que se trae su señorito?

Neleta.- Chesús, María y Chusep! Pobra siñora! Un lio, diu! Bén templa qu’es.
}

\section{Valencia}

Revista bilingüe en un acte i tres quadres, original i en vers de Juan Colom i Sales (1852-1917) amb música del Sr. Sales. Estrenada el dilluns 9 de març de 1891 al teatre Russafa de València.

La nit de l'estrena el programa estava format per la comèdia en dos actes de Juan Colom, Las gemelas, l'estrena de la revista Valencia i l'estrena del sainet en un acte i dos quadres El ciclón d'Emilio S. Pastor, que el podem trobar al llegat de Rafael Culla amb la sig. 2028 (Anònim 1891b: 2). La revista Valencia, apareix sense nom d'autor, el qual hem pogut esbrinar per un anunci del diari (Anònim 1891c: 2). En el llegat Culla, sols es conserva una còpia manuscrita del text sense la part 
musical amb la sig. 561. Sabem que va ser registrada al govern civil de la ciutat a raó del segell que du el manuscrit. Va estar en cartell durant una setmana.

L'obra, segons el llibret manuscrit trobat, esta escrita en un acte, dividit en tres quadres i composta per a trenta personatges, alguns d'ells al legòrics, cors i figurants, els quals son els següents: El Tiempo, El Minuto, El Progresso, La Tradición, La Ilustración, La Libertad, Siglo IV, Siglo XIII, Siglo XIX, Periódico $1^{\circ}$, Periódico $2^{\circ}$, Diario $1^{\circ}, 2^{\circ}, 3^{\circ}, 4^{\circ}$, El parque de bomberos, El enemigo de la Libertad, Nicolás, $D^{a}$ Plaga, Trinida, D. Juan, Un contribuyente, Forastero $1^{\circ}$, Forastero $2^{\circ}$, El de la subasta, Postor $1^{\circ}$, Postor $2^{\circ}$, Torero, $1^{\circ}, 2^{\circ}, 3^{\circ}, 4^{\circ}$, La plaza de toros, Coro de siglos, Coro de fumadores, Coro de obreros, Comparsas, labradores, soldados, pueblo.

Escenografia descrita per l'autor: Quadre primer: El palau d'El Tiempo. Decoració fantàstica. A la dreta, primer terme, un tron amb els atributs del rei dels segles. Al seu costat una tauleta. Al fòrum el gran llibre de la història. Porta a l'esquerra.

En la primera escena apareixen El Tiempo, en el tron, al seu costat El Minuto, i els segles IV, XIII i XIX. ${ }^{3}$ Sona la música i el Coro de los siglos ${ }^{4}$ canta unes estrofes donant pas a la presentació de l'escena en els seus versos.

Aquests primers personatges són al legòrics i representen un tribunal on El Temps és el jutge. En l'escena segona apareix, Valencia, personatge principal que representa a la mateixa ciutat, junt a El Progreso i La Tradición, els seus postulants. Valencia exposarà els dubtes que l'envolten i demanarà consell a El Tiempo sobre quin dels dos pretendents triar.

El Progreso i La Tradición, manifestaran cadascú les seues gestes i motivacions.

Quadre segon: Decoració de carrer o plaça de València. El tron queda en el lloc del quadre anterior.

El Tiempo i Valencia, amb el privilegi de poder ser invisibles, veuran passar la vida de la ciutat i els seus habitants. Comença ací una desfilada de personatges comptant cada un d'ells un succés o un episodi rellevant esdevingut en la ciutat. En aquesta mostra, Valencia descobrirà que és El Progreso amb qui ella vol unir-se:

Valencia.- Que gano, bien se evidencia, pues cuantos me compararon a los tiempos que pasaron hallaron la diferencia. Él solo felíz me hará os lo juro por mi honor!

Tiempo.- ¡Progreso! Dale tu amor!

3 Ací l'autor apunta, los 19 siglos, però nosaltres hem anotat els segles que realment apareixen com a personatges.

4 L'autor no especifica quin cor de tots canta en eixe punt, però creiem que és el cor dels segles degut a l'escena. 


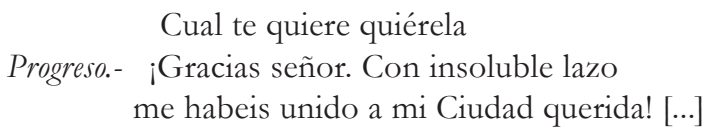

L'obra la classificaríem com a revista d'actualitats. S'apropa al sainet costumista per l'exhibició de les maneres i diferents aspectes de la societat valenciana. La revista realment està escrita en dos quadres, que són els que venen ben descrits i no en tres com marca el títol. El diari de Las Provincias, on anuncia la seua estrena, podem comprovar també que la cita com a revista en un acte i dos quadres. La música ve marcada en quatre intervencions; el Coro de los siglos, el Coro de fumadores i dues de música sola. El cor general és el que tanca l'actuació amb una última estrofa. Ací, donem quasi per fet, que també hi hauria una intervenció musical d'acompanyament, encara que no ve assenyalada. En el llistat de personatges, venen indicats quatre de Diario, però en el text sols apareixen dos. Els personatges que no són al legòrics fan referència a tipus particulars com valencians, madrilenys, andalusos, toreros, amb diàlegs característics de la seua condició.

Colom i Sales, fou autor dramàtic, actor, empresari i professor de declamació del Conservatori de Música de València en concurs obert per a places de nova creació on guanyà la plaça en 1910 (Anònim 1910: 1).

Constanti Llombart, en Los fills de la Morta-Viva, inclou a Colom en els seus biografiats. Conta com Colom, de menut, va estudiar en les Escoles Pies. Aleshores, les necessitats, el feren abandonar els estudis i entrà a treballar en un taller de maquinària. La seua afició al teatre l'expressava escrivint xicotetes obretes que representava als seus amics en teatrets casolans. La seua primera obra impresa, Cuatre còmics d'ocasió, fou escrita quan a penes comptava catorze anys. Començà la seua carrera professional en els escenaris contractats de partiquí en els teatres de Xàtiva i Castelló de la Plana, on estrenà Talis cualis com camalis. A Barcelona va estrenar l'obra Lo que fa la roba. A Alacant les sarsueles, Artistes pa'l Palomó amb música de Francesc Fons i El volantinero amb música de Pau Gorgé, també la peça Vaoro. En Palma de Mallorca, El tio de fora i altres tantes més a la ciutat de València, com El sant del agüelo, El benefisi de Mora, el drama en tres actes Chustisia del sel, Tallarrabos, Per un belluter parat, Un rato de dia de Gloria, L'avarisia romp el sac, Ultima i primera corona, Un madrileño en Alcoy, No cregues ni lo que veches, la sarsuela El Trovaor amb música de Rigoberto Cortina.

A Alacant, actuà i dirigí la companyia amb la qual feu cinc temporades seguides, donant a conèixer el teatre valencià. També feu gira per l'Alger i Portugal. En les últimes línies ens comenta que en els moments d'escriure la seua biografia, Colom estava actuant al teatre Russafa de València (Llombart 1879: 649-654).

En aquesta biografia que ens ha arribat podem extraure que amb vint-i-set anys, Colom ja comptava amb un número considerable i variat d'obres. 
En 1884, junt amb Rafael Lucas Martínez, va escriure la revista, Patricia $i$ compañia, a la que el mestre Ruperto Ruiz de Velasco posà la música. La revista, va ser estrenada en el teatre Principal de Saragossa, on també, en desembre d'eixe mateix any, va estrenar el joguet còmic líric en vers amb música del mateix mestre Ruiz de Velasco, El premio mayor. Aquesta obra la podem consultar en l'arxiu de la University Library of North Carolina at Chapel Hill en www.archive.org.

En 1912, a ral d'exercir de professor de declamació al Conservatori de Música de València, Juan Colom escriu el llibre Soliloquios $i$ Dicelias. Llibre que podem localitzar en el catàleg de la Biblioteca Nacional d'Espanya, però amb data incerta de publicació, atès que aquesta no consta en l'edició. Nosaltres hem pogut esclarir que el llibre va ser publicat en desembre de 1912 (Ariño 1912: 1).

Al llegat de Rafael Culla, hem trobat les seues obres: Si no vols caldo tres tases, sig. 28; Quatre comics d'ocasió (1874), sig. 409; Tal es qualis com camalis (1872), sig. 515; Els conspiradors, sig. 598; La iridectomia (1888), sig. 1973; El sant del agüelo (1881), sig. 2112; El tio cañaules (1909), sig. 2698. Amb música de Pablo Gorgé, El volantinero, sig. 2544. Amb música de Rigoberto Cortina, El trovador (1878), sig. 2496 i El benefisi de Mora (1881) sig. 365.

\section{Conclusions}

La recerca que estem realitzant sobre el teatre en valencià, ens està aportant noves vies per les quals anem teixint fils que de vegades havien estat ocults fins ara. Una d'aquestes vies ha estat la troballa de les obres que ací hem presentat. En aquest treball no hem fet un estudi en profunditat de cadascuna d'elles, ni era el que havíem pretès. Hem mantingut l'escriptura dels títols i dels exemples com els autors ho van escriure. La nostra intenció ha estat la de donar-les a conèixer i omplir el buit que el seu desconeixement havia deixat tot aquest temps. Entren d'aquesta manera a formar part del llistat que els correspon, perquè totes elles són testimoni fidel del teatre noucentista valencià.

Els diaris de l'època, així com les edicions de l'Almanaque de Las Provincias han aportat una documentació molt important a l'hora de poder recompondre la informació de dates, les companyies, les representacions, els autors, etc. Però no sempre ha estat una tasca fàcil. Llavors, la premsa no dedicava molt d'espai a parlar dels actors i actrius, dels qui trobem quasi sempre el primer cognom sense el nom de pila. Tampoc les obres van sempre acompanyades pel nom del seu autor. No obstant això, el testimoni que ens ha deixat és molt valuós i gràcies a ell, en part podem recompondre el nostre passat. 


\section{Fonts documentals}

El llegat de Rafael Culla del Teatre de Russafa de València és un fons privat que actualment es troba en el Centre de Documentació Escènica de la Generalitat Valenciana.

\section{Bibliografia}

Anònim (1 de setembre de 1878) «Teatro-Café Ruzafa», Las Provincias, p. 2.

_. (4 de maig de 1888) «Espectáculos. Teatro de Ruzafa», Las Provincias. p. 4. [consulta 4 febrer 2021]

https:/ / bivaldi.gva.es/va/catalogo_imagenes/grupo.do?posicion=16\&path=1021883\&presentaci on $=$ pagina\&registrardownload $=0$

. (30 de març de 1888a) «Espectáculos. Teatro de Ruzafa», Las Provincias, p. 1. [consulta 4 febrer 2021]

https://bivaldi.gva.es/va/catalogo_imagenes/grupo.do?posicion=117\&path=1021879\&presenta cion $=$ pagina\&registrardownload $=0$

—. (12 de febrer de 1889) «Valencia», Las Provincias, p. 2. [consulta 2 octubre 2019] https:// bivaldi.gva.es/va/catalogo_imagenes/grupo.do?posicion=42\&path=1021901\&presentacion= pagina\&registrardownload $=0$

—_. (1889a). Almanaque de Las Provincias, València, F. Doménech. [consulta: 03 novembre 2018] https://bivaldi.gva.es/es/catalogo_imagenes/grupo.do?posicion=137\&path=1017465

_. (19 de setembre de 1890) «Valencia», Las Provincias, p. 2. [consulta 2 gener 2021]

https:/ / bivaldi.gva.es/va/catalogo_imagenes/grupo.do?posicion=68\&path=1021964\&presentaci on $=$ pagina\&registrardownload $=0$

—. (26 de setembre de 1890a) «Valencia», Las Provincias, p. 2. [consulta 2 gener 2021] https:// bivaldi.gva.es/va/catalogo_imagenes/grupo.do?posicion=94\&path=1021964\&presentacion= pagina\&registrardownload $=0$

—_. (28 de novembre de 1890b) «Valencia», Las Provincias, p. 2. [consulta 4 desembre 2020]

https://bivaldi.gva.es/va/catalogo_imagenes/grupo.do?posicion=102\&path=1021968\&presenta cion $=$ pagina\&registrardownload $=0$

. (29 de desembre de 1890c) «Espectáculos. Teatro de Ruzafa», Las Provincias, p. 1. [consulta 4 desembre 2020].

https://bivaldi.gva.es/va/catalogo_imagenes/grupo.do?posicion=103\&path=1021970\&presenta cion $=$ pagina\&registrardownload $=0$

—. (13 de desembre de 1890d) «Valencia», Las Provincias, p. 2. [consulta 4 de desembre 2020] 
https:/ / bivaldi.gva.es/va/catalogo_imagenes/grupo.do?posicion=46\&path=1021970\&presentaci on $=$ pagina\&registrardownload $=0$

- . (4 de març de 1891) «Valencia», Las Provincias, p. 2. [consulta 2 octubre 2019] https:/ / bivaldi. gva.es/va/catalogo_imagenes/grupo.do?posicion=12\&path=1021976\&presentacion=pagina \&registrardownload $=0$

- (30 de gener de 1891a) «Espectáculos. Teatro de Ruzafa», Las Provincias, p. 2. [consulta 4 de desembre 2020].

https://bivaldi.gva.es/va/catalogo_imagenes/grupo.do?posicion=107\&path=1021972\&presenta cion $=$ pagina\&registrardownload $=0$

—. (8 de març de 1891b) «Valencia» Las Provincias, p. 2. [consulta 2 octubre 2019].

https:/ / bivaldi.gva.es/va/catalogo_imagenes/grupo.do?posicion=28\&path=1021976\&presentaci on $=$ pagina\&registrardownload $=0$

—. (12 de març de 1891c) «Crónica local y general», El Mercantil Valenciano, p. 2.

- . (1892) Almanaque de Las Provincias, València, F.Doménech. [consulta: 03 novembre 2018].

https://bivaldi.gva.es/es/catalogo_imagenes/grupo.do?posicion=208\&path=1017468

_. (1892a) Almanaque de Las provincias, València, F.Donénech. [consulta: 03 novembre 2018]

https:/ /bivaldi.gva.es/es/catalogo_imagenes/grupo.do?posicion=209\&path=1017468

__. (15 d'octubre de 1910) «Valencia», Las Provincias, p. 1. [consulta 2 octubre 2019]

https://prensahistorica.mcu.es/es/catalogo_imagenes/grupo.do?path=1000313371\&presentacio $\mathrm{n}=$ pagina\&posicion $=1 \&$ registrardownload $=0$

Ariño, S. (8 de desembre de 1912) «Un libro de Colom. Soliloquios y Dicelias», El Pueblo, p.1.[consultat: 20 agost 2020]

https://prensahistorica.mcu.es/es/catalogo_imagenes/grupo.do?path=1000197006\&presentacio $\mathrm{n}=$ pagina\&posicion $=1 \&$ registrardownload $=0$

Blasco Laguna, R. (1984) Estudis sobre la literatura del País Valencià (1859-1936), L’Alcúdia, Ajuntament de L'Alcúdia i l'Institut de Filologia Valenciana de la Universitat de València.

Espín Templado, $\mathrm{M}^{a}$ P. (1987) «El sainete del último tercio del siglo XIX. Culminación de un género dramático en el teatro espanyol». Epos: Revista de filologia. Núm. 3, pp. 97-122 [consulta: gener 2021] ISSN 0213-201X.

http://revistas.uned.es/index.php/EPOS/article/view/9486/9042

Guastavino, S; Guastavino, G. (1974) «Un siglo de teatro valenciano. Materiales para su estudio». Revista de archivos bibliotecas y museos. pp. 150-288 [consulta: desembre 2019] Disponible a: http:/ / hemerotecadigital.bne.es/issue.vm?id=0000163178 
Llombart, C. (1879) Los Fills de la Morta-Viva: Apunts Bio-Bibliográfichs pera la Historia del Renaiximent Lliterari Llemosí, València, Emili Pascual [consulta: 03 març 2020]

https://bivaldi.gva.es/es/consulta/registro.do?id=269

Montijano Ruiz, J J. (2013) Madrid Frívolo, Breve Història de la Revista Musical Madrileña y los Teatros que la albergaro, Madrid, La libreria.

Reus Boyd-Swan, F. - Bas Segarra, B. (1994) Fons de Teatre Valencià de la Biblioteca Bas Carbonell, València, Ajuntament de València.

Sales Baviera, J. (2020) «Les vetlades valencianes al Teatre Russafa de València. L'intent de crear un teatre valencià a la Renaixença», Culturas. Revista de Gestión Cultural. vol.7, Núm. 2, pp. 90109 [consulta: gener 2021] https://doi.org/10.4995/cs.2020.14416. https://polipapers.upv.es/ index.php/es/article/view/14416

Sanchis Guarner, M. (1980) Els inicis del teatre valencià modern 1845-187, València, Institut de Filologia Valenciana. Universitat de València. Monografies i assaig.

Sansano, G; Castaño, J. (1997) Sainets Il licitans de la Restauració (1874-1896). Una bistòria del teatre a Elx al llarg del segle XI, Diputació Provincial d'Alacant. Institut de Cultura Juan Gil- Albert.

Sirera, J Ll. (1994) «Del sainet valencià i els seus límits», Aiguadols, L’. Núm. 19, pp. 35-42 [consulta: gener 2021] https://www.raco.cat/index.php/Aiguadolc/article/view/65199/100637

Sirera, J Ll. (1981) Passat, present i futur del teatre valencià, València, Institució Alfons el Magnànim.

Vázquez, A. (1987) Fons de Teatre Valencià a les Biblioteques de Barcelona, Barcelona, Institut del Teatre. Diputació de Barcelona. 